\title{
LA CONVENCIÓN INTERAMERICANA SOBRE LA PROTECCIÓN DE LOS DERECHOS HUMANOS DE LAS PERSONAS ANCIANAS
}

\author{
THE INTER-AMERICAN CONVENTION ON THE PROTECTION OF THE \\ HUMAN RIGHTS OF ELDERLY PERSONS
}

Haideer Miranda Bonilla ${ }^{\mathrm{I}}$

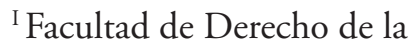 \\ Universidad de Costa Rica. Doctor \\ en Justicia Constitucional y Derechos \\ Fundamentales.
}

\begin{abstract}
Resumen: La presente investigación analiza la importancia que tiene en los derechos humanos, la Convención Interamericana sobre la Protección de los Derechos Humanos de las Personas Mayores para lo cual se estudió su proceso de elaboración, estructura, derechos reconocidos, mecanismos de seguimiento y medios de protección, así como los principales retos que enfrenta a fin de que tenga una plena eficacia en los países de América Latina.
\end{abstract}

Palabras claves: adultos mayores, derechos fundamentales, envejecimiento activo, protección constitucional, protección convencional, Convención Interamericana sobre los Derechos Humanos de las Personas Mayores.

\begin{abstract}
This research analyzes the importance of the InterAmerican Convention on the Protection of the Human Rights of Older Persons in human rights, for which purpose its elaboration process, structure, recognized rights, monitoring mechanisms and means of protection were studied, as well as the main challenges it faces in order for it to be fully effective in Latin American countries.
\end{abstract}

Keywords: senior citizens, fundamental rights, constitucional protection; conventional protection, multilevel protection; Inter-american Convention on Protecting the Human Rights of Older Persons 


\section{Introducción}

La Convención Interamericana sobre la Protección de los Derechos Humanos de las Personas Mayores adoptada en el Cuadragésimo Quinto Período Ordinario de Sesiones de la Asamblea General de la Organización de Estados Americanos que se llevó a cabo el 16 de junio del 2015, es el primer tratado internacional de derechos humanos a nivel mundial y convencional de las personas mayores de carácter vinculante y coercitivo para los Estados. La multiplicidad de las fuentes normativas existentes con anterioridad a este instrumento, su distinta categoría jurídica, alcance regional o variedad de contenido, complejizaban la definición de los derechos mínimos de las personas mayores en los instrumentos internacionales de derechos humanos. Esta divergencia implicaba una serie de dificultades prácticas importantes para los titulares de deberes, y en particular para los Estados, que son los responsables últimos de la adopción de medidas legislativas y normativas para promover los derechos de las personas mayores ${ }^{1}$.

Este instrumento que contempla un amplio y especializado catálogo de derechos humanos "bill of rights" coloca a la Organización de Estados Americanos (OEA) a la vanguardia del derecho internacional de los derechos humanos de las personas mayores y constituye un referente tanto para el trabajo que se desarrolla en las Naciones Unidas, como en otras regiones del mundo ${ }^{2}$. Además, tiene un carácter novedoso pues en este catálogo de derechos se hace referencia a conceptos gerontológicos, y en su proceso de redacción participaron tanto juristas como científicos de la gerontología y el envejecimiento ${ }^{3}$, así como integrantes de la sociedad civil.

En la presente investigación se pretende desarrollar la importancia que tienen en los derechos humanos la Convención Interamericana sobre la Protección de los Derechos Humanos de las Personas Mayores, para lo cual se estudiará su proceso de elaboración, estructura, derechos reconocidos, mecanismos de seguimiento y medios de protección, así como los principales retos que enfrenta a fin de que tenga una plena eficacia.

1 Las opiniones y comentarios contenidos en este artículo no representan necesariamente el criterio oficial de las instituciones en las que el autor labora. El presente estudio fue realizado como resultado de la investigación realizada dentro del proyecto de investigación "La protección constitucional de los adultos mayores en Costa Rica y en América Latina”, número B8A14, inscrito ante el Instituto de Investigaciones Jurídicas de la Facultad de Derecho de la Universidad de Costa Rica. TENDERO BOLLAIN Aida Díaz. Derechos humanos de las personas mayores. Universidad Nacional Autónoma de México, Instituto de Investigación Jurídicas, Comisión Nacional de los Derechos Humanos, México, 2019, p. 93 - 94.

2 ACEVEDO Wendy. El Grupo de Trabajo sobre la Protección de los Derechos Humanos de las Personas Mayores de la Organización de los Estados Americanos, pp. 48 - 49. En HUENCHUAN Sandra y RODRÍGUEZ, Rosa Icela. Autonomía y dignidad en la vejez: teoría y prácticas en políticas de derechos de las personas mayores, Ciudad de México, Naciones Unidas, 2014.

3 TENDERO BOLLAIN Aida Díaz. La nueva Convención Interamericana sobre la Protección de los Derechos Humanos de las Personas Mayores, p. 37. En SOROETA LICERAS Juan. Anuario de los Cursos de Derechos Humanos de Donostia - San Sebastián, vol. XVI, editorial Aranzadi, Madrid, 2016. 


\section{La Convención Interamericana sobre la Protección de los Derechos Humanos de las Personas Mayores}

Este instrumento es pionero en la materia pues introduce un amplio catálogo de derechos, así como novedosos conceptos en materia de envejecimiento y garantiza la protección jurisdiccional de los derechos humanos de las personas mayores por parte de los órganos del Sistema Interamericano de Protección de los Derechos Humanos. Además, tutela la dignidad humana, independencia y autonomía de las personas ancianas y establece una serie de deberes y derechos para las familias y el Estado a fin de que se respete y garantice un envejecimiento activo ${ }^{4}$. Este nuevo tratado rectifica una omisión del derecho internacional de los derechos humanos con relación a este grupo social y estandariza garantías muy relevantes que ningún otro instrumento internacional vinculante había considerado anteriormente de manera explícita en el caso de las personas mayores, como la conjunción entre el derecho a la vida y la dignidad en la vejez, o el derecho a la independencia y la autonomía ${ }^{5}$. Es sorprendente el balance que evidencia entre la dimensión civil, social y política de los derechos, sin subrayar ni obviar ninguna de las dimensiones, también muy en la línea del argumento de que los derechos sociales están entrelazados con los civiles y políticos ${ }^{6}$. Lo anterior en la línea jurisprudencial que ha desarrollado la Corte IDH a partir de los casos Pablote Vílchez vs. Chile ${ }^{7}$ y Lagos del Campo vs. Perú reiterada en otras sentencias.

El objetivo de la Convención es promover, proteger y asegurar el reconocimiento, pleno goce y ejercicio, en condiciones de igualdad, de todos los derechos humanos y las libertades fundamentales de las personas mayores, a fin de contribuir a su plena inclusión, integración y participación en la sociedad. En su preámbulo resalta que todos los derechos humanos y las libertades fundamentales reconocidos en los instrumentos internacionales de derechos humanos se aplican a las personas mayores, pero, como afirma más adelante, la discriminación que sobrelleva la vejez suele impedir que los disfruten plenamente. Para tal efecto, la Convención define la discriminación por edad en la vejez como cualquier distinción, exclusión o restricción basada en la edad que tenga como objetivo o efecto anular o restringir el reconocimiento, goce o ejercicio en igualdad de condiciones de los

4 ROSPI Mimma. Linvecchiamento attivo della popolazione allinterno della coesione sociale tra generazioni: gli strumenti della multilevel governance per nuovi sistemi di welfare. En Rivista della Associazione Italiana Costituzionalisti, número 3, 2018.

5 HUENCHUAN Sandra. Avance en la ratificación de la Convención Interamericana sobre la Protección de los Derechos Humanos de las Personas Mayores en los países de la región, p. 21. En MORA BIERE Tania y HERRERA MUNOZZ Felipe (coordinadores). Convención Interamericana sobre la protección de los derechos humanos de las Personas Mayores: análisis de brechas legislativas y propuestas para su implementación en Chile. Ediciones Servicio Nacional del Adulto Mayor, Santiago, 2018.

6 TENDERO BOLLAIN Aida Díaz. Derechos humanos de las personas mayores, p. 93.

7 Cfr. CLÉRICO Laura y MORALES ANTIONAZZI Mariela. Interamericanización del derecho a la salud. Perspectivas a la luz del caso Poblete de la Corte IDH. Instituto de Estudios Constitucionales de Querétaro, México, 2019. 
derechos humanos y las libertades fundamentales en la esfera política, económica, social, cultural o en cualquier otra esfera de la vida pública y privada.

$\mathrm{Al}$ respecto, en la sentencia número 2016-10235 la Sala Constitucional realizó una extraordinaria síntesis de este instrumento al indicar: "La Convención Interamericana sobre la Protección de los Derechos Humanos de las Personas Mayores, como se desprende de su propio articulado, constituye un instrumento de capital importancia en el contexto del Sistema Interamericano, al desarrollar un expreso reconocimiento de un catálogo de derechos fundamentales para la tutela eficaz de uno de los sectores más vulnerables de la población: las personas adultas mayores; todo ello, en completa afinidad y concordancia con la Constitución Politica, al tener como norte la promoción de la igualdad sustancial de estas personas. La aprobación de esta Convención constituye un importantísimo compromiso para el Estado costarricense y se convierte en herramienta principal de la Jurisdicción Constitucional para la protección de las personas mayores; la Convención involucra y compromete también a la colectividad social y a las familias y enumera una serie de principios, en su articulo tercero, que son las reglas de aplicación e interpretación de los preceptos, a partir de la valorización de la persona mayor, su papel en la sociedad y contribución al desarrollo. Como se pone de manifiesto en el expediente legislativo, esta Convención constituye un hito a nivel internacional sobre la materia. En nuestro derecho interno, se ha utilizado generalmente la terminología de personas adultas mayores, que son las mayores de sesenta y cinco años. De acuerdo con su artículo segundo, la Convención protege aquellas personas de sesenta años o más, salvo que las leyes internas determinen una edad base menor o mayor, siempre que esta no sea superior a los sesenta y cinco años y establece que el concepto incluye, entre otros, el de persona adulta mayor, con lo cual se disipa cualquier duda en cuanto a la conformidad de las disposiciones internas que preceptuan particulares garantías para las personas mayores. Esta Convención, a la vez que un nuevo pilar juridico en la estructura del sistema de derechos, es también un reto para los Estados parte y, específicamente, para Costa Rica. Observe la Asamblea Legislativa que, por disposición del artículo 48 de la Constitución Política, el elenco de derechos reconocidos en la Convención se incorpora a los derechos susceptibles de protección mediante el recurso de amparo".

La responsabilidad de los Estados hacia las personas mayores se hacen más claras y explícitas con este instrumento. En relación a las acciones que se esperan del Estado, se observa que cada derecho contemplado en la Convención va acompañado de una obligación para el Estado. En este instrumento se establece un novedoso mecanismo de seguimiento que consiste en la Conferencia de Estados Parte, que tiene como funciones principales dar seguimiento al avance de los Estados Parte en el cumplimiento de los compromisos, y recibir las recomendaciones del Comité de Expertos. Por su parte, este último órgano colabora en el seguimiento al avance de los Estados Parte en la implementación de la Convención, siendo responsable del análisis técnico de los informes 
presentados por los Estados. Los mecanismos de seguimiento se constituirán cuando el décimo país la ratifique o se adhiera.

\section{El proceso de elaboración}

El interés y la voluntad de los Gobiernos por impulsar un tratado internacional para proteger los derechos humanos de las personas mayores se pronunció de manera formal en la Declaración de Brasilia, aprobada en la Segunda Conferencia Regional Intergubernamental sobre Envejecimiento de América Latina y el Caribe que la Comisión Económica para América Latina y el Caribe (CEPAL) y el Gobierno de Brasil llevaron a cabo en $2007^{8}$. De conformidad con el artículo 26 de la Declaración de Brasilia, la propuesta inicial era lograr el compromiso de crear una Convención Internacional sobre los Derechos de las Personas Mayores.

En la Declaración de Compromiso de Puerto España de abril de 2009, las Jefas y Jefes de Estado y de Gobierno de las Américas se comprometieran a realizar, con el apoyo de la Organización Panamericana de la Salud (OPS) y de la Comisión Económica para América Latina y el Caribe (CEPAL) un examen sobre la viabilidad de elaborar una Convención Interamericana sobre los Derechos de las Personas Mayores. A partir de este momento, los Estados miembros de la O.E.A. iniciaron un diálogo que se reflejó en las decisiones de la Asamblea General de esta organización?.

En el proceso de elaboración de este instrumento se conformó el Grupo de Trabajo de Protección de los Derechos Humanos de las Personas Mayores de la Organización de los Estados Americanos, el cual realizó 58 sesiones de trabajo entre el 2011 - 2015 y estuvo constituida por representantes de las Misiones de Relaciones Exteriores de los Países de la región, además participaron representantes de la Organización Panamericana de la Salud (OPS), la Comisión Económica para América Latina y el Caribe (CEPAL), el Consejo Nacional de las Personas Adultas Mayores (CONAPAM) ${ }^{10}$ y diferentes ONG especializadas en la temática.

Las negociaciones en la elaboración del proyecto de Convención se pueden dividir en tres etapas ${ }^{11}$. La primera ronda de negociaciones duró siete meses (desde septiembre

8 HUENCHUAN Sandra. Avance en la ratificación de la Convención Interamericana sobre la Protección de los Derechos Humanos de las Personas Mayores en los paises de la región, p. 21.

9 HUENCHUAN Sandra. Avance en la ratificación de la Convención Interamericana sobre la Protección de los Derechos Humanos de las Personas Mayores en los países de la región, p. 22.

10 Es el órgano rector en materia de envejecimiento y vejez en Costa Rica que busca garantizar el mejoramiento en la calidad de vida de las personas adultas mayores mediante la formulación y ejecución de las políticas públicas integrales que generen la creación de condiciones y oportunidades para que las personas adultas mayores tengan una vida plena y digna.

11 Esta clasificación es propia de HUENCHUAN Sandra. Los derechos humanos en un contexto de envejecimiento $y$ la protección de los derechos de las personas mayores, p. 105 - 106. En HUENCHUAN Sandra (editora) Envejecimiento, personas mayores y Agenda 2030 para el Desarrollo Sostenible. Perspectiva regional y de derechos humanos. Ed. CEPAL, Naciones Unidad, Santiago de Chile, 2018. 
de 2012 hasta mayo de 2013). Se celebraron 19 reuniones formales y 8 reuniones informales del Grupo de Trabajo. Se analizó el proyecto de convención artículo por artículo y, en varias ocasiones, hubo que revisar la redacción y el contenido. Durante este período, el Grupo examinó gran parte de los párrafos; para algunos se llegó a un acuerdo y otros eran del consenso de la mayoría de las delegaciones, pero quedaron pendientes varios en los que no se había logrado acuerdo. Es por ello que durante la cuadragésima segunda Asamblea General de la OEA se extendió el mandato del Grupo de Trabajo para que prosiguiera con la negociación del proyecto de convención. La segunda etapa de negociaciones (del 5 de septiembre de 2013 al 9 de mayo de 2014) se caracterizó por examinar detenidamente los contenidos del proyecto de convención y ordenar el debate del texto. Con la presidencia a cargo del Representante Alterno de Panamá se realizaron 12 reuniones formales y 2 informales. Además, se dispuso que el Departamento de Derecho Internacional de la OEA y la Comisión Interamericana de Derechos Humanos $(\mathrm{CIDH})$ comentaran el proyecto de Convención que estaba en discusión. En mayo de 2014 se habían aprobado 23 títulos, 11 artículos y 161 párrafos y se habían acordado 3 títulos, 3 artículos y 78 párrafos. Sin embargo, a pesar del avance de las negociaciones, había preocupación en algunos países (Chile, Colombia y Perú, principalmente) por la presunta duplicidad de contenidos dentro del proyecto de convención y con respecto a la Convención Americana de Derechos Humanos, así como otros tratados internacionales.

La tercera etapa se inició el 17 de octubre de 2014, con la presidencia del Representante Alterno de Chile, y concluyó el 15 de mayo de 2015, con la presidencia del Representante Alterno de Panamá. En este período se trabajó sobre la base de un texto que procuraba subsanar las duplicaciones identificadas en la etapa anterior y así facilitar la pronta aprobación del proyecto en la Asamblea General de la OEA en Asunción. Para discutir esta nueva propuesta se realizaron 19 reuniones formales, 2 reuniones informales y una reunión de expertos celebrada el 20 y 21 de abril de 2015 en la sede de la OEA en Washington D.C. Al finalizar el período, todos los artículos del proyecto de Convención quedaron cerrados y aprobados, a pesar de que algunos de ellos se mantuvieron ad referéndum de algunos Estados ${ }^{12}$.

La elaboración de la Convención exigió varias decisiones por parte del Grupo de Trabajo, entre ellas, una de las más importantes fue el enfoque de la redacción. Al respecto, Huenchuan identifica tres opciones: la primera era reiterar el catálogo de derechos humanos de los pactos internacionales, haciendo explícita la referencia a las personas mayores en cada uno de ellos; la segunda era identificar las medidas dirigidas a eliminar la discriminación de la que es objeto este colectivo, y la tercera era profundizar en el significado que los derechos humanos existentes tienen para las personas mayores y a la vez aclarar las obligaciones de los Estados con respecto a la promoción y protección

12 HUENCHUAN Sandra. Los derechos humanos en un contexto de envejecimiento y la protección de los derechos de las personas mayores, p. 106. 
de esos derechos en el contexto del envejecimiento. Este último fue el enfoque que se aplicó $^{13}$.

Otra decisión importante durante las negociaciones del proyecto de elaboración de la Convención era si se crearían o no derechos nuevos ${ }^{14}$. Dentro del Grupo de Trabajo se afirmaba que eso no formaba parte del objetivo de la Convención, pero a medida que se fue ahondando en el texto resultó evidente que no era suficiente agregar a la persona mayor de forma expresa en la redacción de los derechos humanos vigentes. Como consecuencia, el texto ofrece nuevas interpretaciones y amplía los contenidos de los derechos establecidos en los tratados para adaptarlos a las necesidades y reivindicaciones que surgen del envejecimiento de la sociedad ${ }^{15}$

La Convención Interamericana sobre Derechos Humanos de las Personas Mayores fue adoptada en Washington el 15 de junio de 2015, en el marco del cuadragésimo quinto período ordinario de Sesiones de la Asamblea General de la O.E.A. Este instrumento ha sido firmado por Argentina, Brasil, Bolivia, Chile, Costa Rica, El Salvador, Ecuador y Uruguay ${ }^{16}$, y entró en vigor el trigésimo día a partir de la fecha en que se haya depositado el segundo instrumento de ratificación o adhesión de la Convención en la Secretaría General de la Organización de los Estados Americanos ${ }^{17}$. Lo anterior, se llevó a cabo el 12 de noviembre del 2017, tras la ratificación de Uruguay y Costa Rica.

Por otra parte, es un instrumento legal valioso para la comunidad de los países de las Américas, sobre todo porque permite que las personas mayores defiendan y hagan respetar sus derechos en el marco más amplio de la responsabilidad internacional de los Estados. Al respecto, el artículo 36. 1 determina: "Cualquier persona o grupo de personas, o entidad no gubernamental legalmente reconocida en uno o más Estados Miembros de la Organización de los Estados Americanos, puede presentar a la Comisión Interamericana de Derechos Humanos peticiones que contengan denuncias o quejas de violación de alguno de los artículos de la presente Convención por un Estado Parte".

En el caso de una violación de los derechos humanos reconocido en dicho instrumento, el Estado tiene el deber de restituir la situación a su estado normal o reparar el dańo causado por su acción u omisión. De esta manera el Estado compromete su

13 HUENCHUAN Sandra. Avance en la ratificación de la Convención Interamericana sobre la Protección de los Derechos Humanos de las Personas Mayores en los países de la región, p. 24 y 25.

14 Sobre el reconocimiento de nuevos derechos por los jueces constitucionales e interamericanos se puede consultar: MIRANDA BONILLA Haideer y PAZ Cecilia Martha (coordinadores). Constitucionalismo y nuevos derechos, número 38 de la colección de la Asociación Mundial de Justicia Constitucional Editorial Ediciones Nueva Jurídica, 2019, Bogotá, Colombia.

15 HUENCHUAN Sandra. Avance en la ratificación de la Convención Interamericana sobre la Protección de los Derechos Humanos de las Personas Mayores en los países de la región, p. 25.

$16 \mathrm{http}: / /$ www.oas.org/es/sla/ddi/tratados_multilaterales_interamericanos_A70_derechos_humanos_personas_ mayores_firmas.asp

17 En este sentido, Uruguay fue el primer país en depositar su instrumento de ratificación de la Convención. Posteriormente, el segundo depósito del instrumento lo llevó a cabo Costa Rica el 13 de diciembre del 2016, con lo cual la Convención entró en vigor en 30 días para los dos Estados que la han ratificado. 
responsabilidad ante el no cumplimiento de las obligaciones asumidas en observancia de un tratado y tiene el deber de ofrecer reparación frente al sujeto que ha sido lesionado en sus derechos ${ }^{18}$. Ello, en virtud del carácter subsidiario y complementario de la jurisdicción interamericana, a la cual se puede acudir una vez que de previo se han agotado los recursos internos, salvo determinadas excepciones, de conformidad con lo dispuesto en el artículo 46.1 de la Convención Americana ${ }^{19}$.

En este sentido, de conformidad con los principios de subsidiaridad y complementariedad el Estado "es el principal garante de los derechos humanos de la personas, de manera que, si se produce un acto violatorio de dichos derechos, es el propio Estado quien tiene el deber de resolver el asunto a nivel interno y, [en su caso,] reparar, antes de tener que responder ante instancias internacionales como el Sistema Interamericano de Protección de los Derechos Humanos, lo cual deriva del carácter subsidiario que reviste el proceso internacional frente a los sistemas nacionales de garantias de los derechos humanos" ${ }^{20}$.

El carácter complementario de la jurisdicción interamericana significa que "el sistema de protección instaurado por la Convención Americana de Derechos Humanos, no sustituye a las jurisdicciones nacionales, sino que las complementa" ${ }^{21}$. En este sentido, son los Estados los primeros garantes en la protección de los derechos humanos y en particular modo, los tribunales nacionales quiénes tienen que remediar cualquier infracción a un derecho fundamental protegido a nivel constitucional o convencional. El juez nacional ordinario y constitucional actúan como jueces interamericanos, pues representan el primer garante de la aplicación de los derechos reconocidos en la Convención Interamericana sobre Derechos Humanos de las Personas Mayores, pues se encuentra obligado a realizar un control de convencionalidad de oficio y dentro del respectivo marco de sus competencias, lo que conlleva su directa aplicación, así como de los estándares interpretativos desarrollados por la Corte $\mathrm{IDH}^{22}$.

\section{Estructura y derechos reconocidos}

Este instrumento se encuentra conformado por un preámbulo y está dividido en siete capítulos. El capítulo 1 regula lo relacionado con el ámbito de aplicación y el objeto, el cual es promover, proteger y asegurar el reconocimiento y el pleno goce y ejercicio, en

18 HUENCHUAN Sandra. Los derechos humanos en un contexto de envejecimiento y la protección de los derechos de las personas mayores, p. 111.

19 MIRANDA BONILLA Haideer. Derechos Fundamentales en América Latina. Colección Universitaria Centroamericana, número 6. Ed. Jurídica Continental, San José, Costa Rica, 2015, p. 166.

20 Corte IDH. Caso Comunidad Campesina de Santa Bárbara vs. Perú. Excepciones Preliminares, Fondo, Reparaciones y Costas. Sentencia de 1 de septiembre de 2015. Serie C No. 299, párr. 159.

21 Corte IDH. Corte IDH. Caso Duque vs. Colombia. Excepciones Preliminares, Fondo, Reparaciones y Costas. Sentencia de 26 de febrero de 2016. Serie C No. 310, párr. 128.

22 MIRANDA BONILLA Haideer. El control de convencionalidad en el Sistema Interamericano de Derechos Humanos. En Sant'Anna Legal Studies Stals Research Paper 4/2016 En http://www.stals.sssup.it/files/haideer. pdf 
condiciones de igualdad, de todos los derechos humanos y libertades fundamentales de la persona mayor, a fin de contribuir a su plena inclusión, integración y participación en la sociedad. Además, en el artículo 2 establece una serie de definiciones y conceptos gerontológicos de trascendental importancia como "abandono", "cuidados paliativos", "discriminación", "discriminación por edad en la vejez", "discriminación múltiple", "envejecimiento", "envejecimiento activo y saludable", "maltrato", "negligencia", "persona mayor", "persona mayor que recibe servicios de cuidado a largo plazo", "servicios socio sanitarios integrados" y "vejez".

El capítulo II hace referencia a una serie de principios generales que deben respetar las autoridades de los Estados partes en esta materia, en particular: a) La promoción y defensa de los derechos humanos y libertades fundamentales de la persona mayor; b) La valorización de la persona mayor, su papel en la sociedad y contribución al desarrollo; c) La dignidad, independencia, protagonismo y autonomía de la persona mayor; d) La igualdad y no discriminación; e) La participación, integración e inclusión plena y efectiva en la sociedad; f) El bienestar y cuidado; g) La seguridad física, económica y social; h) La autorrealización; i) La equidad e igualdad de género y enfoque de curso de vida; j) La solidaridad y fortalecimiento de la protección familiar y comunitaria; k) El buen trato y la atención preferencial; l) El enfoque diferencial para el goce efectivo de los derechos de la persona mayor; m) El respeto y valorización de la diversidad cultural; n) La protección judicial efectiva; o) La responsabilidad del Estado y participación de la familia y de la comunidad en la integración activa, plena y productiva de la persona mayor dentro de la promoción y defensa de los derechos humanos y libertades fundamentales de la persona mayor, la valorización de la persona mayor, su papel en la sociedad y contribución al desarrollo, la dignidad, independencia, protagonismo y autonomía de la persona mayor, la igualdad y no discriminación, entre otros.

Para Huenchuan este instrumento contempla tres importantes categorías: derechos emergentes, derechos vigentes y derechos extendidos ${ }^{23}$. Los derechos emergentes son nuevos derechos o derechos parcialmente recogidos en la normativa internacional y nacional existente y dentro de ello incluye el derecho a la vida y la dignidad en la vejez (art. 6), el derecho a la independencia y autonomía (art. 7) y el derecho a los servicios de cuidado a largo plazo (art. 12). Por su parte, los derechos vigentes son aquellos ya contemplados en las normas internacionales, pero que requieren cambios para adaptarlos a las necesidades específicas de un colectivo, ya sea por medio de nuevas interpretaciones o mediante la ampliación de su contenido, entre los cuales destaca la igualdad y la no discriminación (art. 5), el consentimiento libre e informado en el ámbito de la salud (art. 11) y la seguridad y la vida sin violencia (arts. 9 y 10). Los derechos extendidos está dirigidos específicamente a colectivos que hasta entonces no habían disfrutado

23 HUENCHUAN Sandra. Avance en la ratificación de la Convención Interamericana sobre la Protección de los Derechos Humanos de las Personas Mayores en los paises de la región, p. 28. 
de ellos, por omisión o discriminación, entre los cuales destaca lo relacionado con la accesabilidad y la movibilidad de las personas y lo relacionados con las situaciones de riesgo y emergencias humanitarias ${ }^{24}$.

Por su parte, el capítulo III señala los deberes generales de los Estados parte. El IV capítulo se refiere en forma amplia y precisa a los derechos protegidos, entre los cuales destacan: igualdad y no discriminación por razones de edad (art. 5), derecho a la vida digna y a la dignidad en la vejez (art. 6), derecho a la independencia y a la autonomía (art. 7), derecho a la participación e integración comunitaria (art. 8), derecho a la seguridad y a una vida digna sin ningún tipo de violencia (art. 9), derecho a no ser sometido a tortura, ni a penas o tratos crueles, inhumanos o degradantes (art. 10), derecho a brindar consentimiento libre e informado en el ámbito de la salud (art. 11), derecho de la persona mayor que recibe servicios de cuidado a largo plazo (art. 12), derecho a la libertad personal (art. 13), derecho a la libertad de expresión y de la opinión y al acceso a la información (art. 14), derecho a la nacionalidad y a la libertad de circulación (art. 15), derecho a la privacidad y a la intimidad (art. 16), derecho a la seguridad social (art. 17), derecho al trabajo (art. 18), derecho a la salud (art. 19), derecho a la educación (art. 20), derecho a la cultura (art. 21), derecho a la recreación, al esparcimiento y al deporte (art. 22), derecho a la propiedad (art. 23), derecho a la vivienda (art. 24), derecho a una medio ambiente sano (art. 25), derecho a la accesibilidad y a la movilidad personal (art. 26), derechos políticos (art. 27), derecho a la reunión y de asociación (art. 28), situación de riesgo y emergencias humanitarias (art. 29), igual reconocimiento como persona ante la ley (art. 30) y acceso a la justicia (art. 31).

El capítulo $\mathrm{V}$ hace mención a la toma de conciencia, en particular, el artículo 32 determina: "Los Estados Parte acuerda: a) Adoptar medidas para lograr la divulgación y capacitación progresiva de toda la sociedad sobre la presente Convención. b) Fomentar una actitud positiva hacia la vejez y un trato digno, respetuoso y considerado hacia la persona mayor $y$, sobre la base de una cultura de paz, impulsar acciones de divulgación, promoción de los derechos y empoderamiento de la persona mayor, así como evitar el lenguaje e imágenes estereotipadas sobre la vejez. c) Desarrollar programas para sensibilizar a la población sobre el proceso de envejecimiento y sobre la persona mayor, fomentando la participación de ésta y de sus organizaciones en el diseño y formulación de dichos programas. d) Promover la inclusión de contenidos que propicien la compresión y aceptación de la etapa del envejecimiento en los planes y programas de estudios de los diferentes niveles educativos, así como en las agendas académicas y de investigación. e) Promover el reconocimiento de la experiencia, la sabiduría, la productividad y la contribución al desarrollo que la persona mayor brinda a la sociedad en su conjunto".

24 HUENCHUAN Sandra. Avance en la ratificación de la Convención Interamericana sobre la Protección de los Derechos Humanos de las Personas Mayores en los paises de la región, p. 29. 
Por su parte, el capítulo VI determina los mecanismos de seguimiento de la Convención y los medios de protección y el capítulo VII se refiere a las disposiciones generales.

\section{Mecanismos de seguimiento y medios de protección}

En cuanto a los mecanismos de seguimiento el artículo 33 determina: "Con el fin de dar seguimiento a los compromisos adquiridos y promover la efectiva implementación de la presente Convención se establece un mecanismo de seguimiento integrado por una Conferencia de Estados Parte y un Comité de Expertos. El Mecanismo de Seguimiento quedará constituido cuando se haya recibido el décimo instrumento de ratificación o adhesión. Las funciones de la secretaría del Mecanismo de Seguimiento serán ejercidas por la Secretaría General de la Organización de los Estados Americanos”.

La Conferencia de Estados Parte es el órgano principal del mecanismo de seguimiento, está integrada por los Estados Parte en la Convención y de conformidad con el numeral 34 de la convención tiene las siguientes funciones: “a) Dar seguimiento al avance de los Estados Parte en el cumplimiento de los compromisos emanados de la presente Convención; b) Elaborar su reglamento y aprobarlo por mayoría absoluta; c) Dar seguimiento a las actividades desarrolladas por el Comité de Expertos y formular recomendaciones con el objetivo de mejorar el funcionamiento, las reglas y procedimientos de dicho Comité; d) Recibir, analizar y evaluar las recomendaciones del Comité de Expertos y formular las observaciones pertinentes; e) Promover el intercambio de experiencias, buenas prácticas y la cooperación técnica entre los Estados Parte con miras a garantizar la efectiva implementación de la presente Convención; f) Resolver cualquier asunto relacionado con el funcionamiento del Mecanismo de Seguimiento”.

Por su parte, el Comité de Expertos de conformidad con el numeral 35 estará integrado por un especialista designado por cada uno de los Estados Parte en la Convención y tendrá las siguientes funciones: “a) Colaborar en el seguimiento al avance de los Estados Parte en la implementación de la presente Convención, siendo responsable del análisis técnico de los informes periódicos presentados por los Estados Parte. A tales efectos, los Estados Parte se comprometen a presentar un informe al Comité de Expertos con relación al cumplimiento de las obligaciones contenidas en la presente Convención, dentro del año siguiente de haberse realizado la primera reunión. De allí en adelante, los Estados Parte presentarán informes cada cuatro ańos; b) Presentar recomendaciones para el cumplimiento progresivo de la Convención sobre la base de los informes presentados por los Estados Parte de conformidad con el tema objeto de análisis; c) Elaborar y aprobar su propio reglamento en el marco de las funciones establecidas en el presente artículo".

La Conferencia de Estados Partes y el Comité de Expertos analizarán y formularán recomendaciones sobre la base de los informes presentados por los Estados partes, un 
esfuerzo conjunto que se traduce en un círculo virtuoso para la vigencia de los derechos que integran la Convención y, sobre todo, en una herramienta fundamental para la comprensión de las medidas legislativas, políticas, programáticas y de otra índole que se requieren de cada Estado parte para garantizar esos derechos en el ámbito nacional25.

\section{La entrada en vigor}

La Convención Interamericana sobre Derechos Humanos de las Personas Mayores fue adoptada en Washington el 15 de junio de 2015, en el marco del cuadragésimo quinto período ordinario de Sesiones de la Asamblea General de la O.E.A. Este instrumento ha sido firmado por Argentina, Brasil, Bolivia, Chile, Costa Rica, El Salvador, Ecuador y Uruguay, y entró en vigor el 12 de enero del 2017, cuando se cumplió el trigésimo día a partir de la fecha en que se haya depositado el segundo instrumento de ratificación o adhesión de la Convención en la Secretaría General de la Organización de los Estados Americanos. Este instrumento normativo tiene como principal reto que otros Estados lo ratifiquen a fin de que en América Latina existan estándares mínimos de protección en esta materia y que pueda entrar en vigor el mecanismo de seguimiento integrado por una Conferencia de Estados Parte y un Comité de Expertos para lo cual es necesario que se haya recibido el décimo instrumento de ratificación o adhesión.

\section{Conclusiones}

Il tempo presente ha rivoluzionato i rapporti tra le età della vita. Dei giovani è il presente e il futuro. Chi viene dal passato è un intruso. Bisogna prolungare la giovinezza fin che si può e con ogni mezzo. Questa contrazione annulla l'età matura, l'età della pienezza $^{26}$. El envejecimiento no es una enfermedad, sino un proceso gradual que se desarrolla durante el curso de la vida y que conlleva cambios biológicos, fisiológicos, psicosociales y funcionales de variadas consecuencias, las cuales se asocian con interacciones dinámicas y permanentes entre el sujeto y su medio ${ }^{27}$. La vejez no ser vista como algo negativo.

La Convención Interamericana sobre la Protección de los Derechos Humanos de las Personas Mayores, es el primer tratado internacional de derechos humanos a nivel mundial y convencional de las personas mayores de carácter vinculante y coercitivo para los Estados que viene a unificar la multiplicidad de las fuentes normativas particularmente de soft law existentes con anterioridad y además resalta la importancia de garantizar un

25 HUENCHUAN Sandra. Los derechos humanos en un contexto de envejecimiento y la protección de los derechos de las personas mayores, p. 113.

26 ZAGREBELSKY Gustavo. Sensa adulti. Ed. Einaudi, Turín, 2016, p. 22.

27 Convención Interamericana sobre Protección de los Derechos Humanos de las Personas Adultas. 
envejecimiento activo. Este instrumento que contempla un amplio catálogo de derechos humanos coloca a la Organización de Estados Americanos a la vanguardia del derecho internacional de los derechos humanos de las personas mayores, pues que la persona, a medida que envejece, debe seguir disfrutando de una ayuda plena, independiente y autónoma, con salud, seguridad, integración y participación activa en las esferas económica, social, cultural y política de sus sociedades. Tiene un carácter novedoso pues en este catálogo de derechos se hace referencia a conceptos gerontológicos, y en su proceso de redacción participaron tanto juristas como científicos de la gerontología y el envejecimiento ${ }^{28}$. Además, es pionera pues introduce un amplio catálogo de derechos como la dignidad humana, independencia y autonomía de las personas ancianas y establece una serie de deberes y derechos para las familias y el Estado, incorpora novedosos conceptos en materia de envejecimiento activo y garantiza la protección jurisdiccional de los derechos humanos de las personas mayores dentro del Sistema Interamericano de Protección de los Derechos Humanos.

La obligación de respetar los derechos humanos de las personas mayores requiere que los Estados partes se abstengan de elaborar leyes, políticas, normas, programas, procedimientos administrativos y estructuras institucionales que, ya sea de forma directa o indirecta, priven a las personas mayores del goce de sus derechos civiles, políticos, económicos, sociales y culturales. Lo anterior requiere que los Estados partes protejan a las personas mayores frente a la discriminación por parte de actores privados y que adopten medidas directamente orientadas a eliminar las prácticas consuetudinarias y de cualquier otra índole que alimenten los prejuicios y perpetúen la noción de inferioridad o dependencia de las personas mayores. La obligación de cumplir con los derechos requiere que los Estados partes adopten una amplia gama de medidas (incluidas medidas especiales de carácter temporal, cuando proceda, de conformidad con el artículo 4, literal b, de la Convención) para asegurar que las personas mayores gocen de jure y de facto de esos derechos ${ }^{29}$.

Este instrumento normativo tiene como principal reto que otros Estados lo ratifiquen a fin de que en América Latina existan estándares mínimos de protección en esta materia y que pueda entrar en vigor el mecanismo de seguimiento integrado por una Conferencia de Estados Parte y un Comité de Expertos para lo cual es necesario que se haya recibido el décimo instrumento de ratificación o adhesión. Asimismo es necesario potenciar las obligaciones de toma de conciencia que al efecto dispone el artículo 32 de la convención.

28 TENDERO BOLLAIN Aida Díaz. La nueva Convención Interamericana sobre la Protección de los Derechos Humanos de las Personas Mayores, p. 37. En SOROETA LICERAS Juan. Anuario de los Cursos de Derechos Humanos de Donostia - San Sebastián, vol. XVI, editorial Aranzadi, Madrid, 2016.

29 HUENCHUAN Sandra. Los derechos humanos en un contexto de envejecimiento y la protección de los derechos de las personas mayores, p. 120. 
En el ámbito de la tutela jurisdiccional de los derechos fundamentales ${ }^{30}$, los jueces ordinarios, constitucionales e interamericanos y todas las autoridades nacionales tienen la importante misión de salvaguardar los derechos fundamentales previstos en la Convención Interamericana sobre la Protección de los Derechos Humanos de las Personas Mayores en aquellos ordenamientos jurídicos que ha la han suscrito en el marco del control de convencionalidad que deben de llevar a cabo ${ }^{31}$. En este sentido, se evidencia como algunas jurisdicciones constitucionales en América Latina han reconocido una especial protección a las personas mayores en su jurisprudencia ${ }^{32}$, lo cual se ha extendido recientemente en la jursidicción convencional interamericana con la sentencia Poblete Vílchez vs. Chile ${ }^{33}$. Lo anterior, se llevó a cabo a través de un diálogo judicial que potencia la utilización de derecho comparado ${ }^{34}$ entre las jurisdicciones constitucional y convencional, pues los jueces interamericanos citarón resoluciones de los órganos de justicia constitucional de Argentina, Costa Rica y México. En este sentido, la Convención será una luz para los impartidores de justicia o jueces de distintos niveles, que mayoritariamente resuelven asuntos relacionados con las personas mayores que pertenecen a la jurisdicción civil, penal y familiar ${ }^{35}$ y en particular a cualquier jurisdicción.

\section{Bibliografía}

BOBBIO Norberto. L'eta dei diritti. Ed. Eunadi, Torino, 1999.

CLÉRICO Laura y MORALES ANTIONAZZI Mariela. Interamericanización del derecho a la salud. Perspectivas a la luz del caso Poblete de la Corte IDH. Instituto de Estudios Constitucionales de Querétaro, México, 2019.

CRUZ CASTRO Fernando. El juez constitucional como garante del control de convencionalidad. En curso de publicación en la Revista Judicial, número 128, Corte Suprema de Justicia, San José.

FRANCHI Giovanni. La tutela giuridica degli anziani non autosufficienti e delle persone affette da alzheimer. Key Editore, 2016.

30 PIZZORUSSO, Alessandro. Justicia constitucional y tutela jurisdiccional de los derechos, p. 11 - 32. En Revista Judicial, número 118, enero, 2016, Corte Suprema de Justicia, Costa Rica.

31 CRUZ CASTRO Fernando. El juez constitucional como garante del control de convencionalidad. En curso de publicación en la Revista Judicial, número 128, Corte Suprema de Justicia, San José.

32 MIRANDA BONILLA Haideer. La tutela de los ancianos en el ámbito constitucional y convencional en América Latina, p. 81 - 97. CUCARELLA GALIANA Luis Andrés (Coordinador). "Desafíos procesales en el constitucionalismo moderno (convencionalidad y eficacia de la justicia”. Editorial Nueva Jurídica, Colección de la Asociación Mundial de Justicia Constitucional, número 39, Bogotá, 2019.

33 Corte IDH. Caso Poblete Vilches y otros vs. Chile. Fondo, Reparaciones y Costas. Sentencia de 8 de marzo de 2018. Serie C No. 349.

34 MIRANDA BONILLA Haideer y ULATE CHACÓN Enrique. El juez constitucional como comparatista. En Revista de Derecho Constitucional Comparado, editorial número 2/2020, Ed. IJ Editores, Buenos Aires.

35 TENDERO BOLLAIN Aida Díaz. La nueva Convención Interamericana sobre la Protección de los Derechos Humanos de las Personas Mayores, p. 53. 
HUENCHUAN Sandra (editora). Los derechos de las personas mayores en el siglo XXI: situación, experiencias y desafios. Ed. CEPAL, Naciones Unidas, Ciudad de México, 2012.

HUENCHUAN Sandra (editora). Envejecimiento, personas mayores y Agenda 2030 para el Desarrollo Sostenible. Perspectiva regional y de derechos humanos. Ed. CEPAL, Naciones Unidad, Santiago de Chile, 2018.

- Avance en la ratificación de la Convención Interamericana sobre la Protección de los Derechos Humanos de las Personas Mayores en los paises de la región, p. 20 - 37. En MORA BIERE Tania y HERRERA MUÑOZ Felipe (coordinadores). Convención Interamericana sobre la protección de los derechos humanos de las Personas Mayores: análisis de brechas legislativas y propuestas para su implementación en Chile. Ediciones Servicio Nacional del Adulto Mayor, Santiago, 2018.

HUENCHUAN Sandra y RODRÍGUEZ-PIÑERO Luis (Editora). Envejecimiento y derechos humanos: situación y perspectivas de protección. Comisión Económica para América Latina y el Caribe (CEPAL), Chile, 2010.

HUENCHUAN Sandra y ROODRIGUEZ, Rosa Icela. Autonomia y dignidad en la vejez: teoria y prácticas en politicas de derechos de las personas mayores, Ciudad de México, Naciones Unidas, 2014.

MIRANDA BONILLA Haideer. Derechos Fundamentales en América Latina. Colección Universitaria Centroamericana, número 6. Ed. Jurídica Continental, San José, Costa Rica, 2015.

- El control de convencionalidad en el Sistema Interamericano de Derechos Humanos. En Sant'Anna Legal Studies Stals Research Paper 4/2016 En http://www.stals.sssup.it/files/ haideer.pdf

- La tutela de los ancianos en el ámbito constitucional y convencional en América Latina, p. 81 - 97. CUCARELLA GALIANA Luis Andrés (Coordinador). "Desafíos procesales en el constitucionalismo moderno (convencionalidad y eficacia de la justicia”. Editorial Nueva Jurídica, Colección de la Asociación Mundial de Justicia Constitucional, número 39, Bogotá, 2019.

MIRANDA BONILLA Haideer y ULATE CHACÓN Enrique. El juez constitucional como comparatista. En Revista de Derecho Constitucional Comparado, editorial número 2/2020, Ed. IJ Editores, Buenos Aires.

MORA BIERE Tania y HERRERA MUÑOZ Felipe (coordinadores). Convención Interamericana sobre la protección de los derechos humanos de las Personas Mayores: análisis de brechas legislativas y propuestas para su implementación en Chile. Ediciones Servicio Nacional del Adulto Mayor, Santiago, 2018. 
LASARTE ÁLVAREZ Carlos (Director). La protección de las personas mayores. Ed. Tecnos, 2007.

PAVESI Nicoletta. La tutela degli anziani. Ed. Erickson, 2013.

MIRANDA BONILLA Haideer y PAZ Cecilia Martha (coordinadores). Constitucionalismo y nuevos derechos, número 38 de la colección de la Asociación Mundial de Justicia Constitucional Editorial Ediciones Nueva Jurídica, 2019, Bogotá, Colombia.

PIZZORUSSO, Alessandro. Justicia constitucional y tutela jurisdiccional de los derechos, p. 11 - 32. En Revista Judicial, número 118, enero, 2016, Corte Suprema de Justicia, Costa Rica.

ROSPI Mimma. L'invecchiamento attivo della popolazione all'interno della coesione sociale tra generazioni: gli strumenti della multilevel governance per nuovi sistemi di welfare. En Rivista della Associazione Italiana Costituzionalisti, número 3, 2018. En: https://www. rivistaaic.it/images/rivista/pdf/3_2018_Rospi.pdf

TENDERO BOLLAIN Aida Díaz. La nueva Convención Interamericana sobre la Protección de los Derechos Humanos de las Personas Mayores, p. 27 - 55. En SOROETA LICERAS Juan. Anuario de los Cursos de Derechos Humanos de Donostia - San Sebastián, vol. XVI, editorial Aranzadi, Madrid, 2016.

- Derechos humanos de las personas mayores. Universidad Nacional Autónoma de México, Instituto de Investigación Jurídicas, Comisión Nacional de los Derechos Humanos, México, 2019

ZAGREBELSKY Gustavo. Sensa adulti. Ed. Einaudi, Turín, 2016.

\section{CORTE INTERAMERICANA DE DERECHOS HUMANOS}

Corte IDH. Caso Comunidad Campesina de Santa Bárbara vs. Perú. Excepciones Preliminares, Fondo, Reparaciones y Costas. Sentencia de 1 de septiembre de 2015. Serie C No. 299.

Corte IDH. Corte IDH. Caso Duque vs. Colombia. Excepciones Preliminares, Fondo, Reparaciones y Costas. Sentencia de 26 de febrero de 2016. Serie C No. 310.

Corte IDH. Caso Poblete Vilches y otros vs. Chile. Fondo, Reparaciones y Costas. Sentencia de 8 de marzo de 2018. Serie C No. 349.

\section{SALA CONSTITUCIONAL DE COSTA RICA}

Sentencia número 2016-10235 